\title{
COLORIMETRIA E PERMEAMETRIA APLICADAS À AVALIAÇAO DAS ROCHAS ORNAMENTAIS BUTTERFLY BEIGE E BUTTERFLY GREEN SUBMETIDAS AO ENVELHECIMENTO ACELERADO.
}

\author{
COLORIMETRY AND PERMEAMETRY APPLIED TO EVALUATION OF DIMENSION STONES \\ BUTTERFLY BEIGE AND BUTTERFLY GREEN SUBJECT TO ACCELERATED AGING.
}

\author{
Thiago M. BOLONINI ${ }^{1}$; Antonio M. GODOY ${ }^{2}$; Carlos Alberto M. FIGUEIREDO ${ }^{3}$; \\ António MAURÍCIO ${ }^{3}$; Manuel F. PEREIRA ${ }^{3}$ \\ ${ }^{1}$ Universidade Federal do Espirito Santo. Centro de Ciências Jurídicas Econômicas, Depto de Gemologia. End.: Av. Fernando \\ Ferrari, 514 - Goiabeiras, Vitória - ES. Email: thiago.bolonini@ufes.br \\ ${ }^{2}$ Universidade Estadual Paulista, Av. 24-A, 1.515. Rio Claro-SP, Brasil. Email: mgodoy@rc.unesp.br \\ ${ }^{3}$ Centro de Petrologia e Geoquímica do Instituto Superior Técnico - IST, Av. Rovisco Pais no 1 , Lisboa, Portugal. \\ Email: carlos.m.figueiredo@ist.utl.pt,pcd2045@ist.utl.pt,mfcp@ist.utl.pt

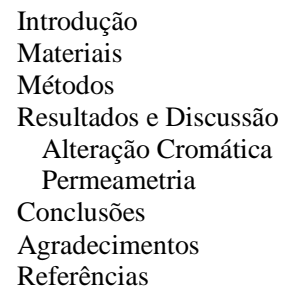

RESUMO - Os quartzo-sienitos hiperstênio conhecidos comercialmente como Butterfly Beige e Butterfly Green são extraídos no município de Barra de São Francisco, Estado do Espírito Santo - Brasil. Neste trabalho, ao longo do ensaio de envelhecimento acelerado em câmara com atmosfera saturada em $\mathrm{SO}_{2}$, foram realizadas medições de cor (Padrão CIELab - $\Delta \mathrm{E}, \Delta \mathrm{L}, \Delta \mathrm{a}, \Delta \mathrm{b}$ e; reflectância espectral) para quantificação das modificações estéticas causadas pelo ataque físico-químico na câmara e o monitoramento da permeabilidade " $C$ " (permeametria por intrusão a gás - constante de permeabilidade de Darcy) dos litotipos. A substância química agressiva presente no sistema é produto fotoquímico do $\mathrm{SO}_{2}$, o $\mathrm{H}_{2} \mathrm{SO}_{4}$ (ácido sulfúrico), e seu objetivo é o de simular reações que acontecem durante a exposição das rochas às chuvas ácidas. Deste experimento resultaram alterações estéticas significativas no Butterfly Green que, por se tratar de uma rocha escura, sofreu uma perda considerável de cor ( $\Delta \mathrm{E}$ após 100 ciclos $=3,87)$ ficando mais clara $(\Delta \mathrm{L}$ após 100 ciclos $=3,57)$ devido também às variações de "a", que mostrou sua coloração verde $(\Delta \mathrm{a}$ após 100 ciclos $=-0,45)$ e de "b" $(\Delta b$ após 100 ciclos $=1,43$ ) que definiu o amarelamento causado na rocha, ambos corroborados pela maior reflectância entre os 550 e 590 nm. Para o Butterfly Beige as consequências das alterações foram menos nocivas, pois, por ter um tom claro, apresentou quase que metade da variação na iluminância $(\Delta \mathrm{L}$ após 100 ciclos $=1,98)$ verificada no Green. As variações de "a" $(\Delta \mathrm{a}$ após 100 ciclos $=-0,07)$ e de "b" ( $\Delta$ b após 100 ciclos $=-0,93)$ mostram que a rocha ficou no campo entre o verde e o azul. O mineral que mais influenciou estes resultados foi o ortoclásio presente tanto no Butterfly Beige quanto no Green. Quanto à permeabilidade o Butterfly Green apresentou maior valor acumulado $(C=0,0097)$ ao longo dos ciclos na câmara, seguido do Butterfly Beige $(C=0,0095)$.

Palavras-chave: Colorimetria, Permeametria, Envelhecimento acelerado, Rocha ornamental.

ABSTRACT - The quartz-syenites with hypersthene commercially known as Butterfly Beige and Green, are extracted in Barra de São Francisco, Espirito Santo State - Brazil. In this work, along the accelerated aging test in chamber with $\mathrm{SO}_{2}$ saturated atmosphere were performed: color measurements (CIELab Standard - $\Delta \mathrm{E}, \Delta \mathrm{L}, \Delta \mathrm{a}, \Delta \mathrm{b}$ and spectral reflectance) for quantification of the aesthetic changes caused by physical - chemical attack in the chamber and; monitoring permeability " $C$ " (Gas intrusion permeametry - Darcy's permeability constant) of the rock types. The aggressive chemical agent in the system is an $\mathrm{SO}_{2}$ photochemical product, the $\mathrm{H}_{2} \mathrm{SO}_{4}$ (sulfuric acid), and its purpose is to simulate reactions that occur during exposure of rocks to acid rain. This experiment resulted in significant aesthetic changes on Butterfly Green, because it is a dark rock, suffered a considerable color loss $(\Delta \mathrm{E}=3.87$ after 100 cycles $)$ getting lighter $(\Delta \mathrm{L}$ after 100 cycles $=3.57)$, also due to the variations of "a", which showed its green $(\Delta \mathrm{a}=-0.45$ after 100 cycles) and "b" ( $\Delta \mathrm{b}=1.43$ after 100 cycles) that defined the yellowing caused on rock surface, both supported by the higher reflectance between 550 and $590 \mathrm{~nm}$. For the Butterfly Beige the alteration consequences were less harmful, because it have a clear tone, showed almost half of the variation in luminance ( $\Delta \mathrm{L}=1.98$ after 100 cycles) checked in Green. Changes in "a" $(\Delta \mathrm{a}=-0.07$ after 100 cycles) and "b" $(\Delta \mathrm{b}=$ 0.93 after 100 cycles) showed that the rock was inside green and yellow field respectively. The mineral that most influenced these findings was the orthoclase identified both in the Butterfly Beige, as in Green. About the permeability, the Butterfly Green showed higher cumulative value $(C=0.0097)$ along the cycles in the chamber, followed by Butterfly Beige $(C=0.0095)$.

Keywords: Colorimetry, Permeametry, Accelerated aging, Dimension stone.

\section{INTRODUÇÃO}

O envelhecimento acelerado é descrito em Torquato et al. (2008) como uma forma de apressar 0 processo laboratorial de envelhecimento de rochas sãs, tendo em vista a avaliação de suas resistências ao intemperismo, face aos danos causados pelas variações de temperatura e umidade na presença de uma atmosfera saturada em dióxido de enxofre 
$\left(\mathrm{SO}_{2}\right)$, simulando regiões industrializadas.

Tais danos são tratados por Grossi et al. (1999), onde mostram que o envelhecimento de rochas para revestimento e pedras de cantaria em ambientes urbanos pode estar associado à deposição de poluentes sob a forma de gases ácidos e partículas sobre as superfícies das rochas.

Estudos de alteração realizados por Simão (2003) e Simão et al. (2010) em rochas ígneas demonstraram que, mesmo rochas aparentemente sãs, podem apresentar problemas de degradação rápida quando submetidas a ambientes quimicamente agressivos ou a climas com características peculiares.

Tais modificações são traduzidas na perda de qualidade da rocha e este tipo de estudo propicia a qualificação das rochas ornamentais face aos agentes agressivos da atmosfera. Sethi (1971), Takahashi et al. (1975a, b), Kasahara \& Takahashi (1976) e McGraw (1982) demonstram que o $\mathrm{SO}_{2}$, em presença de umidade e luz permite a nucleação de partículas, fotoquimicamente formadas, de ácido sulfúrico $\left(\mathrm{H}_{2} \mathrm{SO}_{4}\right)$.

Figueiredo et al. (2005) e Torquato et al. (2008) utilizaram o mesmo processo automatizado de envelhecimento acelerado em câmara com atmosfera saturada em $\mathrm{SO}_{2}$ utilizado, com algumas adaptações, neste trabalho em concomitância com a medição de cor a exemplo de Figueiredo et al. (2004).

Os objetivos deste estudo são, em suma, avaliar o comportamento da cor e da permeabilidade das rochas ornamentais Butterfly Beige e Butterfly Green, correspondentes a duas variedades de quartzosienitos com hiperstênio, submetidas ao envelhecimento acelerado pelo confinamento de amostras padronizadas em câmara climática com atmosfera saturada em $\mathrm{SO}_{2}$. $\mathrm{O}$ estudo também visa o melhor entendimento da influência da variação da composição mineralógica e, sobretudo, da coloração original destas rochas no controle e intensidade das variações das referidas propriedades quando submetidas a atmosferas agressivas.

\section{MATERIAIS}

As rochas ornamentais estudadas são extraídas no distrito de Itaperuna, Município de Barra de São Francisco, Estado do Espírito Santo, Brasil, em um maciço ígneo que aflora sob a forma de um corpo intrusivo alongado com aproximadamente $35 \mathrm{~km}$ de eixo maior de direção NE-SW (Figura 1).

$\mathrm{O}$ referido maciço intrusivo insere-se no contexto do Orógeno Araçuaí (Pedrosa-Soares et al., 1992, 2001, 2006, 2007; Martins et al., 2004; Marshak et al., 2006; Alkimin et al., 2007; Noce et al., 2007); Roncato Júnior (2009); CPRM (2007), e integraria a Suíte G5, de idade Cambriana, possivelmente equivalente a Suíte Intrusiva Aimorés de natureza charnockitoide descrita por Pedrosa-Soares et al. (2007) no âmbito da folha geológica de Mantena-MG (Figura 1).

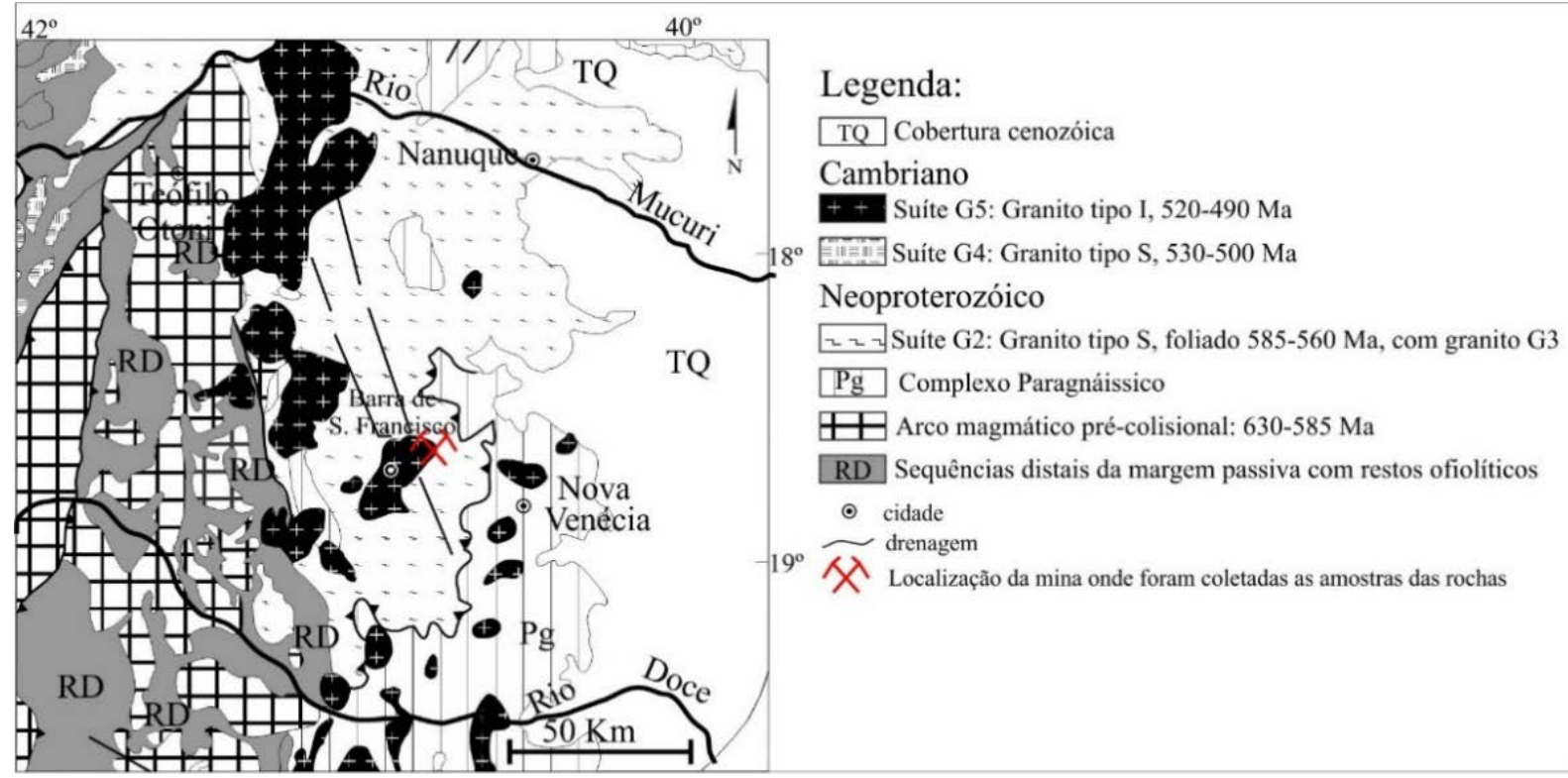

Figura 1 - Localização e contexto geológico do maciço intrusivo fonte das rochas ornamentais estudadas. A figura é um recorte da porção central do Orógeno Araçuaí. O recorte limita-se a oeste na direção das sedes dos municípios de Governador Valadares e Manhuaçu. Fonte: Modificado de Pedrosa-Soares et al. (2007). 
As duas rochas ornamentais estudas são comercializadas sob denominações Butterfly Beige e Butterfly Green e correspondem a variedades de quartzo sienitos com hiperstênio de color bege e verde, respectivamente (Figura 2).

Tratam-se de rochas com aspectos petrográficos e mineralógicos bastante similares, diferenciando-se principalmente pelas colorações exibidas. Estes litotipos encontram-se detalhados em Bolonini (2015), Bolonini et al. (2016a, b, c), Bolonini \& Godoy (2017) e Bolonini et al. (2017).

A rocha Butterfly Beige exibe textura

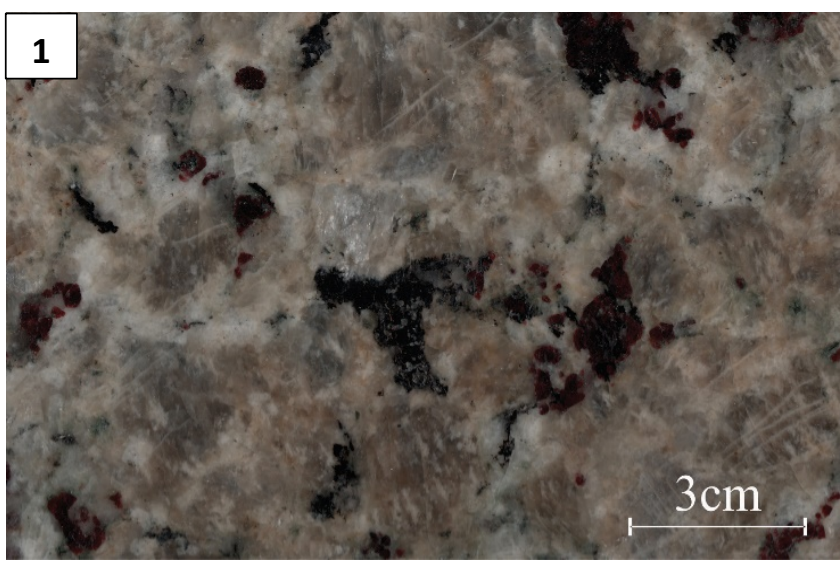

fanerítica inequigranular, de granulação grossa a porfirítica com cristais que variam de $0,2 \mathrm{~cm}$ a $4,5 \mathrm{~cm}$, de coloração bege, estrutura isotrópica, composta por ortoclásio (62\%), plagioclásio (22\%), quartzo (11\%), granada (3\%) biotita e hiperstênio (2\%). A variedade Butterfly Green apresenta textura fanerítica inequigranular, alotriomórfica, de granulação grossa a porfirítica com cristais que variam de $0,2 \mathrm{~cm}$ a $4 \mathrm{~cm}$, de coloração verde, estrutura isotrópica, composta por ortoclásio (58\%), plagioclásio (20\%), quartzo (13\%), granada (6\%) biotita e hiperstênio (3\%).

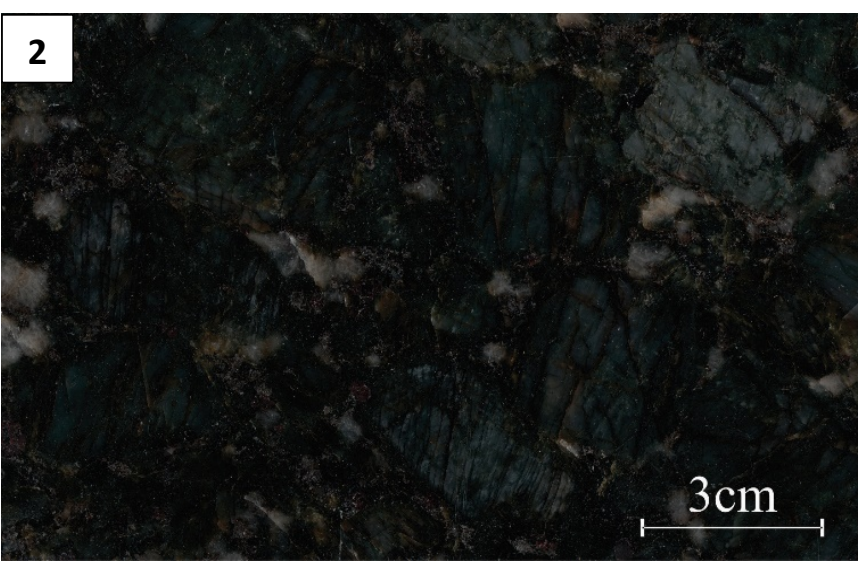

Figura 2 - Aspectos estéticos das rochas polidas Butterfly Beige e Butterfly Green.

\section{MÉTODOS}

Para os testes de envelhecimento acelerado, cujas avaliações foram fundamentalmente embasadas nas alterações cromáticas exibidas pelas rochas ornamentais, foram utilizados 5 corpos de prova com formato de paralelepípedo com arestas medindo $2 \mathrm{~cm}, 10 \mathrm{~cm}$ e $15 \mathrm{~cm}$ para cada uma das rochas. Para determinação da permeabilidade foi utilizado 1 corpo de prova cilíndrico com $1,5 \mathrm{~cm}$ de altura e $4,5 \mathrm{~cm}$ de diâmetro. A câmara climática utilizada foi a Fitoclima 300EDTU Aralab, configurada (Tabela
1) para passar por períodos intercalados de 7 horas com temperatura interna de $60^{\circ} \mathrm{C}$ e $30 \%$ de umidade (seguimentos 4 e 5) e 6 horas com $25^{\circ} \mathrm{C}$ e $95 \%$ de umidade (seguimento 6), com concentração constante de gás $\left(\mathrm{SO}_{2}\right)$ em 25 ppm.

Esses períodos analisados equivalem, ao tempo diário médio de insolação a que as rochas são submetidas (das 5:30h às $18: 30$ h e.g.) e o tempo excedente (seguimentos 1, 2, 5 e 7) é o que a câmara gasta para ligar e se estabilizar nas configurações de temperatura e umidade.

Tabela 1. Configuração do teste de envelhecimento acelerado.

\begin{tabular}{c|c|c|c|c|c|c|c}
\hline \multirow{2}{*}{ Propriedade } & \multicolumn{9}{|c}{ Um ciclo* (segmentos) } \\
\cline { 2 - 8 } & $\mathbf{1}$ & $\mathbf{2}$ & $\mathbf{3}$ & $\mathbf{4}$ & $\mathbf{5}$ & $\mathbf{6}$ & $\mathbf{0 7}$ ** \\
\hline Temperatura ( $\mathbf{(}^{\mathbf{C})}$ & 25 & 25 & 60 & 60 & 25 & 25 & 25 \\
\hline Umidade (\%) & 95 & 95 & 30 & 30 & 95 & 95 & 95 \\
\hline Tempo (h) & 0 & 1 & 1 & 6 & 1 h 30 min & 6 & 1 min. \\
\hline Próximo segmento & 2 & 3 & 4 & 5 & 6 & 3 & 7 \\
\hline
\end{tabular}

Notas: *Depois do $6^{\circ}$ segmento, o programa retorna para o $3^{\circ}$ ao $6^{\circ}$ por 24 vezes antes de ir para o $7^{\circ}$ e último segmento; ** Este segmento irá rodar depois de completados os outros ciclos ( $3^{\circ}$ ao $6^{\circ}$ segmento), ou seja, no $25^{\circ}$ ciclo.

A câmara foi programada para realizar períodos ininterruptos de 25 ciclos, com avaliações visuais entre as exposições. O dióxido de enxofre $\left(\mathrm{SO}_{2}\right)$ em presença de luz ultravioleta, oxigênio e umidade, é fotoquimicamente transformado (Kasahara \&
Takahashi, 1976) no ácido sulfúrico $\left(\mathrm{H}_{2} \mathrm{SO}_{4}\right)$ presente nas chuvas ácidas. A câmara foi programada para realizar períodos ininterruptos de 25 ciclos, com avaliações visuais entre as exposições. O dióxido de enxofre $\left(\mathrm{SO}_{2}\right)$ em presença de luz ultravioleta, oxigênio e 
umidade, é fotoquimicamente transformado (Kasahara \& Takahashi, 1976) no ácido sulfúrico $\left(\mathrm{H}_{2} \mathrm{SO}_{4}\right)$ presente nas chuvas ácidas. A perda de massa foi calculada através da equação 1 e representada em porcentagem.

$$
(\Delta \mathrm{p})=\frac{M n-M o}{M o} \times 100 \quad \text { Equação (1). }
$$

A relação de todos os procedimentos adotados, adaptados da norma CEN199X (1995), pode ser visualizada na tabela 2 .

$\mathrm{Na}$ aquisição dos dados (medições, obser- vações, anotações e interpretações acerca da ausência ou do surgimento de peculiaridades em cada corpo de prova, amostra ou litotipo) foram utilizadas, além da câmara Fitoclima 300EDTU, a câmera Nikon Coolpix P510, a lupa binocular óptica Nikon SMZ645, o Espectrofotômetro Konica Minolta CM-500i, o Permeâmetro por intrusão a gás GP-M100A da PMI - Porous Materials, Inc. e a impressora multifuncional Epson com resolução máxima de $600 \mathrm{dpi}$.

Tabela 2 - Etapas e procedimentos adotados para realização dos trabalhos.

\begin{tabular}{|c|c|c|c|}
\hline & Natural & 50 ciclos & 100 ciclos \\
\hline \multirow{9}{*}{ 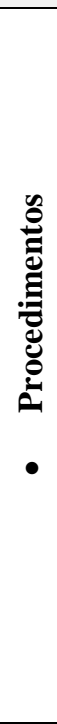 } & $\begin{array}{l}\text { Pesagem } \\
\end{array}$ & Retirada da câmara & Retirada da câmara \\
\hline & Secagem por 24h (até a massa constante) & Pesagem & Pesagem \\
\hline & Pesagem e cálculo da perda de massa & $\begin{array}{l}\begin{array}{l}\text { Secagem por 24h (até a massa } \\
\text { constante) }\end{array} \\
\end{array}$ & $\begin{array}{l}\text { Secagem por 24h (até a massa } \\
\text { constante) }\end{array}$ \\
\hline & $\begin{array}{l}\text { Aquisição e digitação dos dados de cor } \\
\text { (CIELab e reflectância espectral - } 75 \\
\text { pontos por litotipo). }\end{array}$ & $\begin{array}{l}\text { Pesagem e cálculo da perda de } \\
\text { massa }\end{array}$ & $\begin{array}{l}\text { Pesagem final e cálculo da perda de } \\
\text { massa. }\end{array}$ \\
\hline & $\begin{array}{l}\text { Digitalização das superfícies dos corpos } \\
\text { de prova }\end{array}$ & $\begin{array}{l}\text { Aquisição e digitação dos dados } \\
\text { de cor (CIELab e reflectância } \\
\text { espectral - } 75 \text { pontos por litotipo). }\end{array}$ & $\begin{array}{l}\text { Aquisição e digitação dos dados de } \\
\text { cor (CIELab e reflectância } \\
\text { espectral - } 75 \text { pontos por litotipo). }\end{array}$ \\
\hline & Medição da permeabilidade (C) & $\begin{array}{l}\text { Digitalização das superfícies dos } \\
\text { corpos de prova }\end{array}$ & $\begin{array}{l}\text { Digitalização das superfícies dos } \\
\text { corpos de prova }\end{array}$ \\
\hline & $\begin{array}{l}\text { Observação e fotografia em lupa óptica } \\
\text { binocular. }\end{array}$ & Medição da permeabilidade (C) & Medição da permeabilidade (C) \\
\hline & Inserção na câmara & $\begin{array}{l}\text { Observação e fotografia em lupa } \\
\text { óptica binocular. }\end{array}$ & Observação e fotografia em lupa \\
\hline & & Inserção na câmara & \\
\hline
\end{tabular}

Antes de todas as medições, com o ponto e pelo padrão de cor utilizado CIELab espectrofotômetro, foi feita uma calibração do (Hunterlab, 2008).

equipamento com o padrão fornecido pela própria A aquisição dos dados de cor obtidos e empresa. As configurações de medição são enumerados na tabela 3 foi feita com o uso de definidas pelo ângulo do observador $\left(10^{\circ}\right)$, pela uma malha de medição (gabarito) elaborada de quantidade de medidas (8) feitas pelo acordo com as medidas dos corpos de prova, espectrofotômetro para definição da média (valor perfazendo um total de 15 aquisições por corpo de final de medição) de cor e reflectância para cada prova, por ciclo.

Tabela 3 - Configurações e propriedades medidas pelo espectrofotômetro.

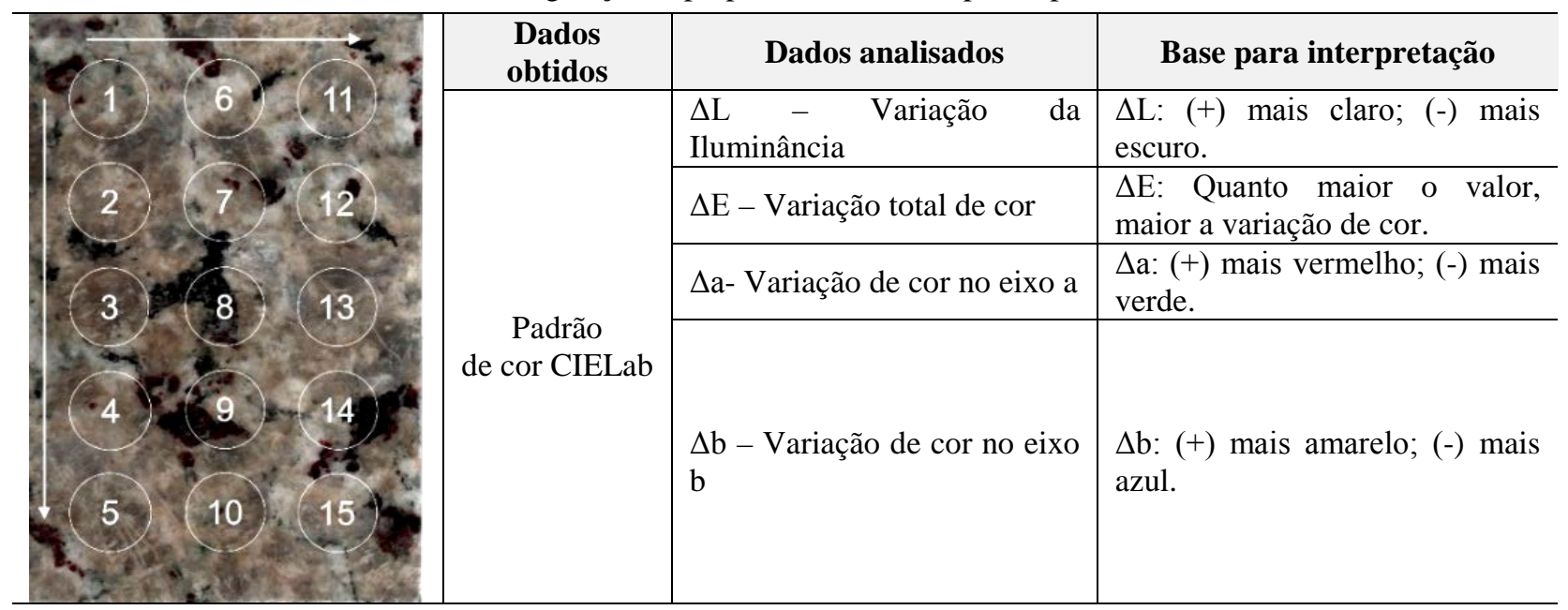

Obs.: As setas brancas indicam o sentido em que foram feitas as aquisições. Este procedimento foi respeitado em todas as aquisições, em todos os corpos de prova 
Depois de feitas as aquisições nas amostras ao natural, foram feitas as identificações dos minerais presentes no centro de cada ponto de medição para avaliar a influência destes no comportamento da cor.

A constante de permeabilidade $(C)$, que é a propriedade que uma rocha possui de permitir a passagem de fluidos sem comprometimento de sua estrutura ou o deslocamento de suas partes foi obtida, conforme ilustrado na figura 3, com base na equação 2 (PMI, 1996).

$$
\boldsymbol{C}=\frac{\mathbf{8 F T V}}{\boldsymbol{B D}^{2}\left(\boldsymbol{P}^{2}-\mathbf{1}\right)} \quad \text { Equação (2) }
$$

Em que: $\boldsymbol{C}=$ Constante de permeabilidade de Darcy; $\mathbf{F}=$ Fluxo; $\mathbf{T}=$ Espessura do corpo de prova; $\mathbf{V}=$ Viscosidade do gás $\left(\mathrm{NO}_{2}=0,0185\right) ; \mathbf{D}$ $=$ Diâmetro do corpo de prova; $\mathbf{P}=$ Pressão (atmosferas).

$\mathrm{O}$ teste consiste em injetar gás $\left(\mathrm{NO}_{2}\right)$ a alta pressão e medir o que consegue atravessar o corpo de prova (Figura 3A) com o uso do permeâmetro por intrusão a gás (Figura 3B).

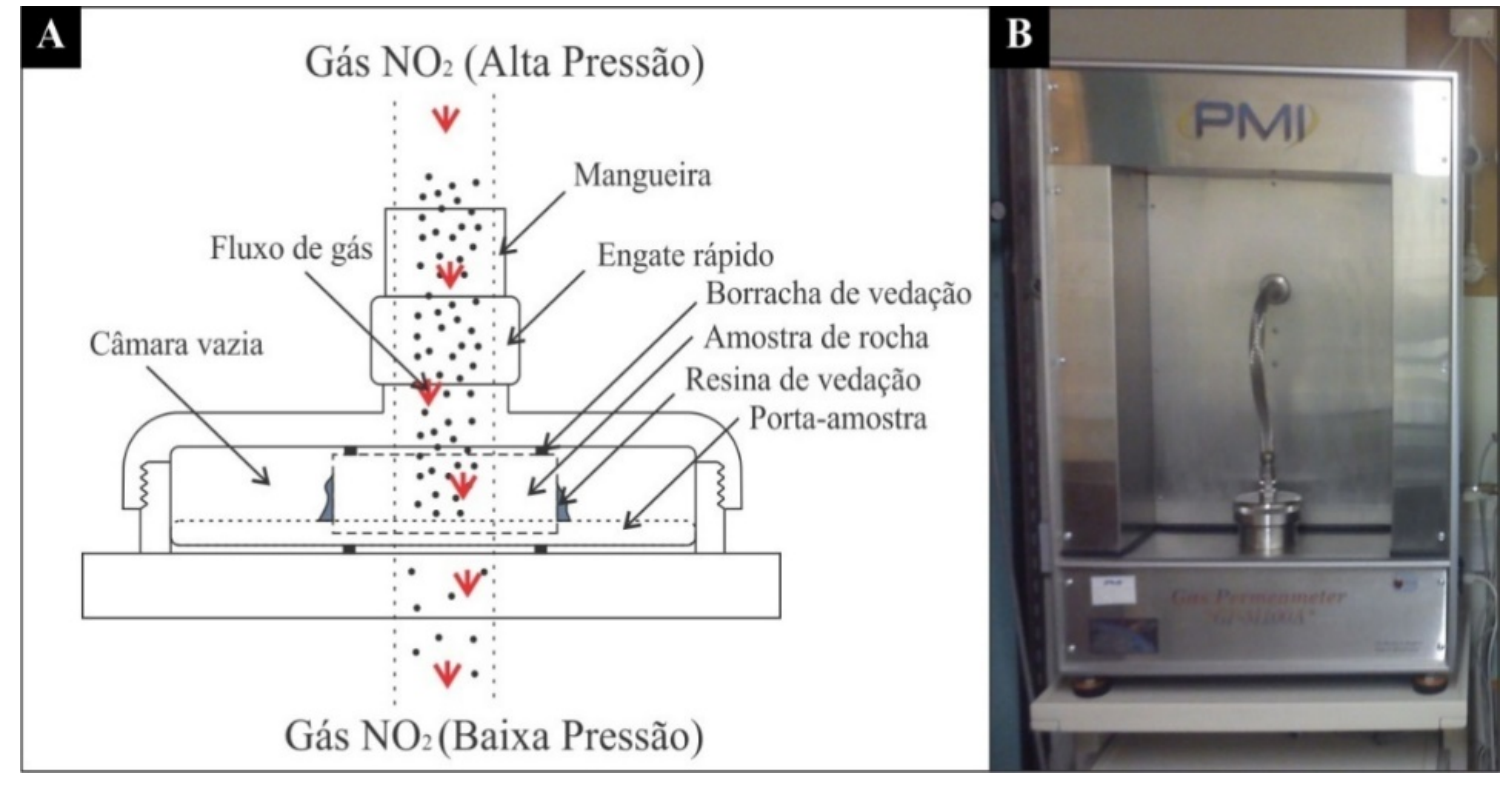

Figura 3 - Ilustração do método de medição da permeabilidade no permeâmetro a gás.

Legenda: A) Esquema interno demonstrativo do fluxo do gás na técnica de medição; B) Equipamento do laboratório.

\section{RESULTADOS E DISCUSSÃO}

\section{Alteração Cromática}

As figuras 4 e 5 representam as superfícies digitalizadas dos corpos de prova expostas ao teste de envelhecimento acelerado. Nelas é possível visualizar a evolução da alteração cromática ao longo dos ciclos no teste.

O Butterfly Beige (Figura 4) mostra um clareamento da superfície à medida que aumentam os ciclos de exposição à atmosfera saturada em dióxido de enxofre.
Essa constatação pode ser confirmada no gráfico de reflectância espectral (Figura 4), onde: à medida que aumentam os ciclos de exposição, diminui a contribuição das cores no espectro visível, aproximadamente, entre os comprimentos de onda $400 \mathrm{~nm}$ e $495 \mathrm{~nm}$ que correspondem às regiões do violeta e do azul. Esse efeito pode estar associado à limpeza da superfície, reflexo da corrosão provocada pelo $\mathrm{H}_{2} \mathrm{SO}_{4}$.

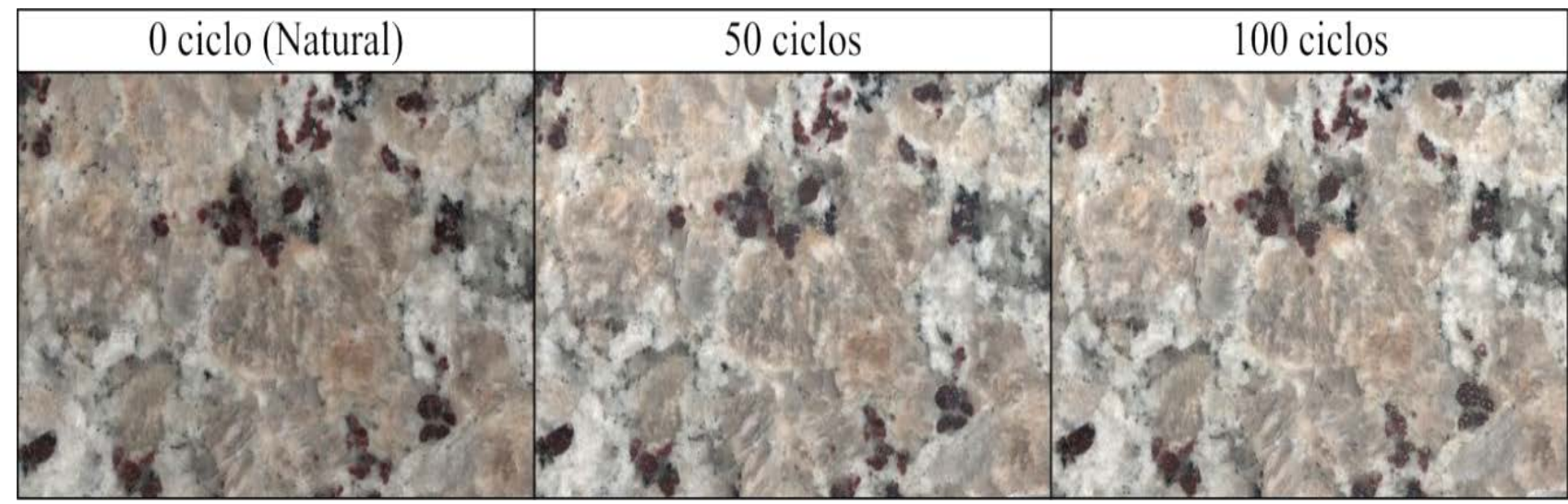

Figura 4 - Ilustração do resultado do envelhecimento acelerado para o Butterfly Beige. 
Na figura 5 pode-se notar o dano causado pela cristalização de sais à aparência estética do litotipo polido Butterfly Green.

A reflectância espectral medida (Figuras 6A, 6B) bem como a variação da iluminância (Figuras 7A, 7B) mostram um leve e regular clareamento nas superfícies das amostras, com uma pequena exceção na reflectância espectral do Butterfly Green entre os 550 e 590 nm (Figura 6B), dados corroborados pelos $\Delta \mathrm{L}$ positivos (8,51 nos primeiros 50 ciclos e 3,57 de variação total).

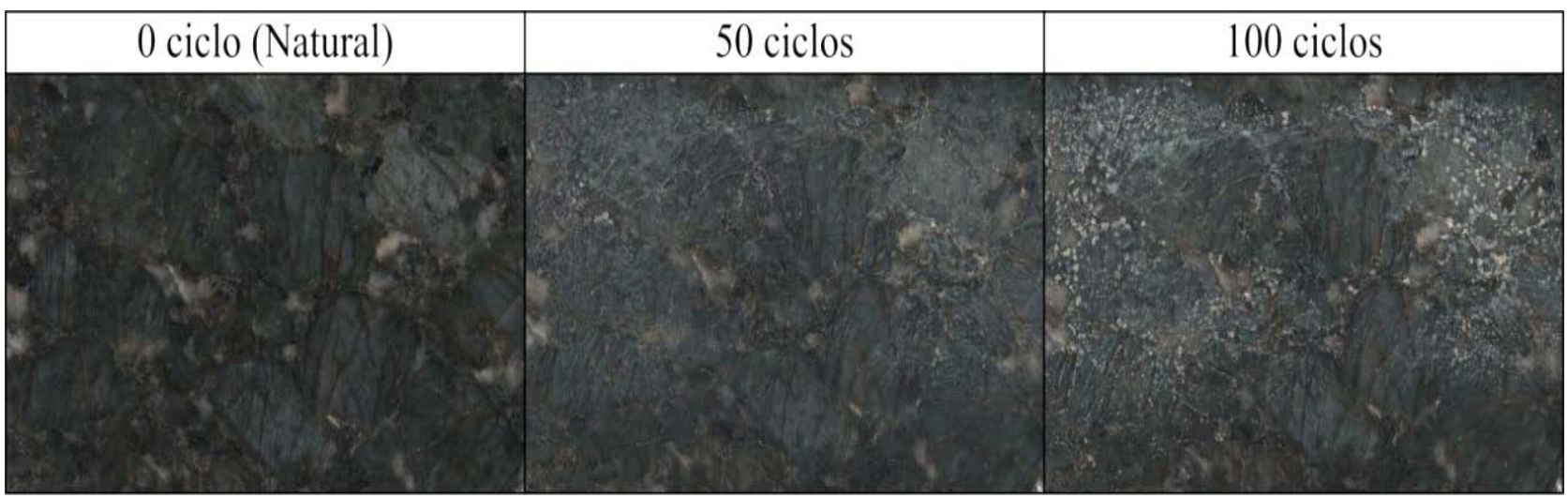

Figura 5 - Ilustração do resultado do envelhecimento acelerado para o Butterfly Green.

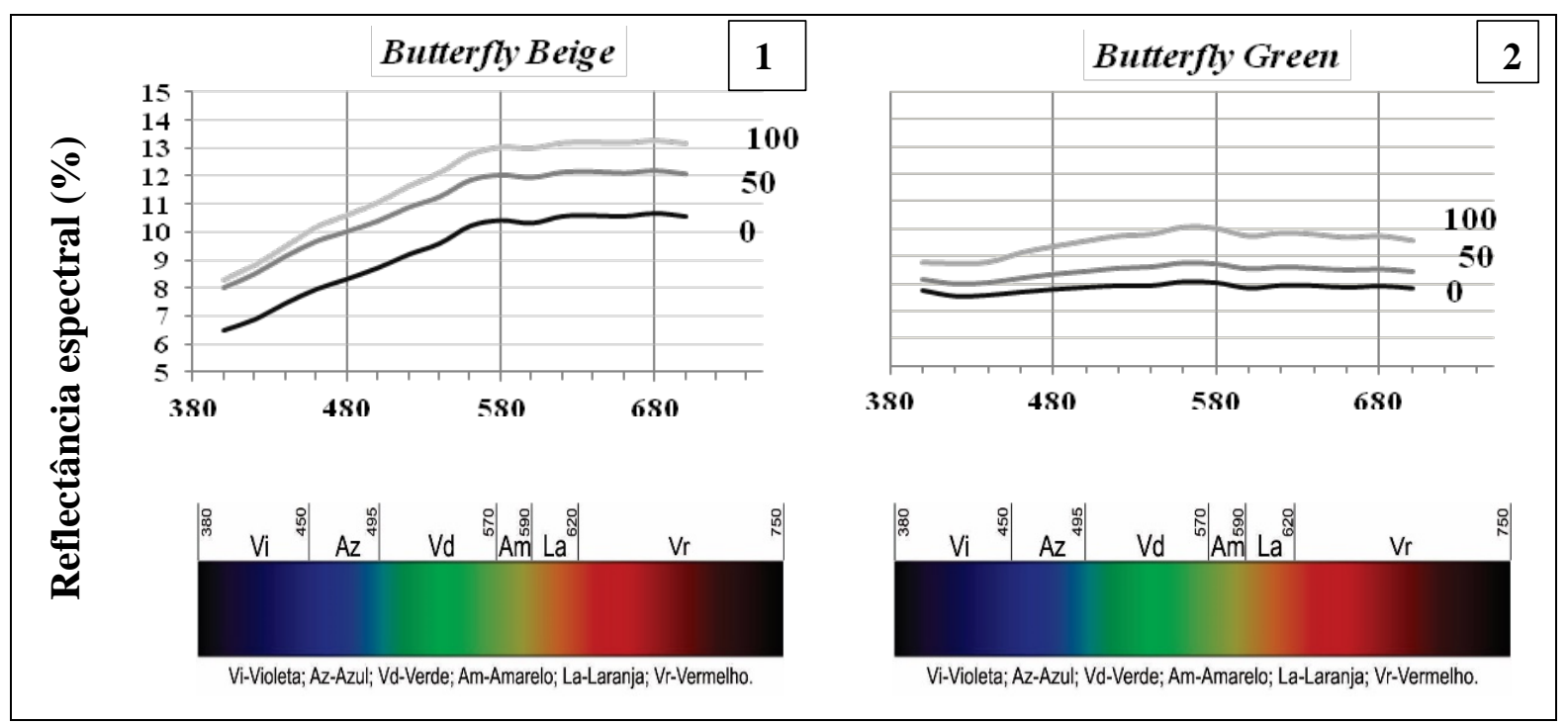

Figura 6 - Evolução da reflectância espectral ao longo dos ciclos de envelhecimento acelerado na câmara com atmosfera saturada em $\mathrm{SO}_{2}$ Legenda: Os números dentro do gráfico indicam os ciclos de envelhecimento (0 ou natural, 50 e 100 ciclos).

Quando comparado ao Butterfly Green, o Beige obteve valores menores de variação nos parâmetros colorimétricos (Figura 7A). Os valores de variação dos parâmetros "a" e "b" sugerem que tanto o Beige quanto o Green tiveram, mesmo após os 100 ciclos de envelhecimento, variações sutis com $\Delta \mathrm{a}=-0,07$ e $\Delta \mathrm{b}=-0,93$ para o Beige e $\Delta \mathrm{a}=-0,45$ e $\Delta \mathrm{b}=$ 1,43 para o Green.

A variação total de cor mostra a rocha que mais sofreu alteração no padrão de cor.

Em todos os intervalos de ciclos $(0-50$ e 0 100), o Butterfly Green obteve a maior variação $(\Delta \mathrm{E}=8,51$ nos primeiros 50 ciclos e de 3,87 após os 100 ciclos) em relação ao Beige $(\Delta \mathrm{E}=$ 2,08 após os primeiros 50 ciclos e $\Delta \mathrm{E}=2,18$ após os 100 ciclos), o que permite dizer que o Beige, de modo geral, teve suas características estéticas menos danificadas quando 0 comparamos ao Butterfly Green (Figura 7B).

Na identificação dos minerais presentes nos pontos de medição de cor, o ortoclásio foi o mineral mais frequente tendo o Beige 43\% (Figura 8A) e o Green 72\% (Figura 8B).

O controle de massa permitiu avaliar a perda/ganho de massa ao longo dos ciclos, mostrando que houve para o Butterfly Green, com valores pequenos, duas situações:

Corrosão superficial e no interior de micro- 
descontinuidades, nos primeiros 50 ciclos, evidenciada pela perda de massa (Figura 9A, B); II.

Na sequência (últimos 50 ciclos) houve a nas amostras, cristalização de sulfetos nas superfícies dos cristais corroídos e no interior de planos de descontinuidades (Figuras 10A, B). Para o Butterfly Beige também foi identificada

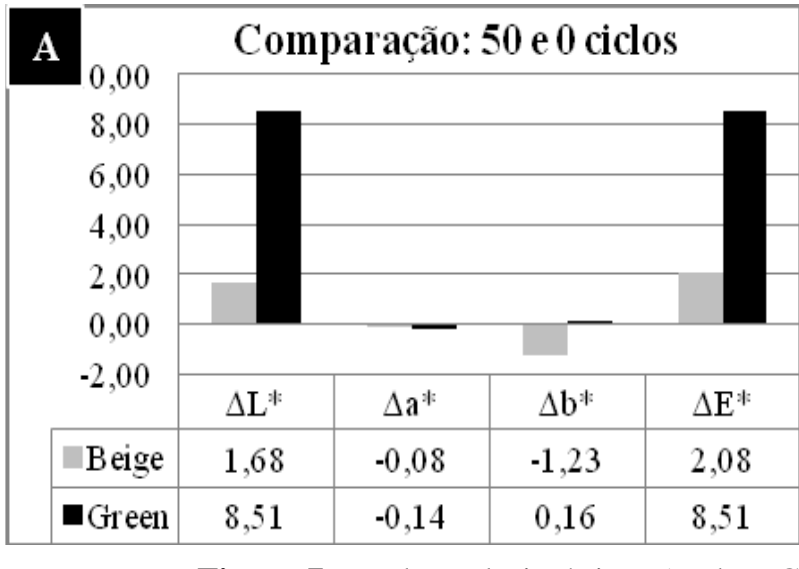

Figura 7 - Dados colorimétricos (Padrão CIELab) para as rochas submetidas ao ensaio.

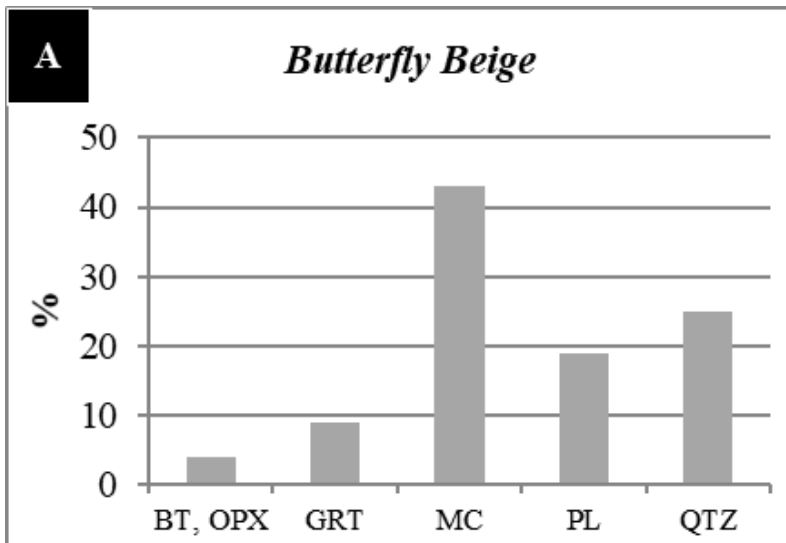

uma incipiente perda de massa, provavelmente ocasionada pela corrosão superficial de alguns minerais como, por exemplo, cristais de granada (Figuras 10C, D), biotita e hiperstênio devido às eletronegatividades e às reatividades dos metais presentes em suas composições químicas (Fe, Mg nos cristais de hiperstênio e biotita), com ácidos.

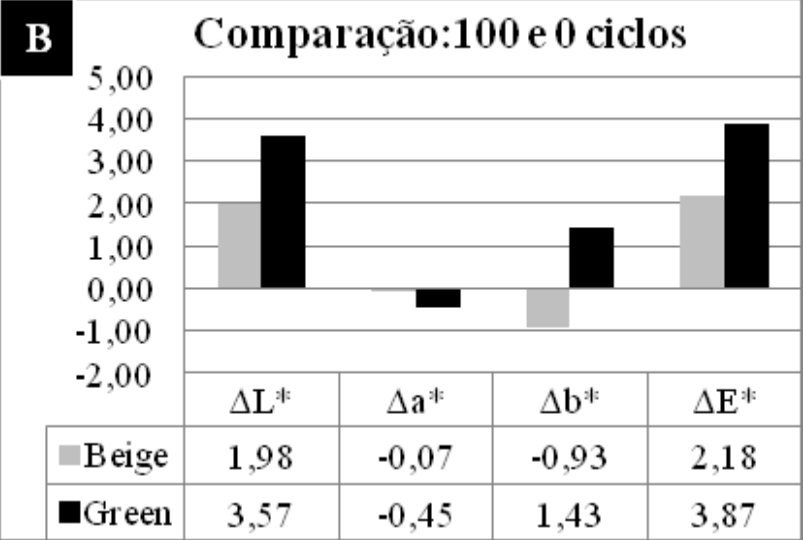

Butterfly Green

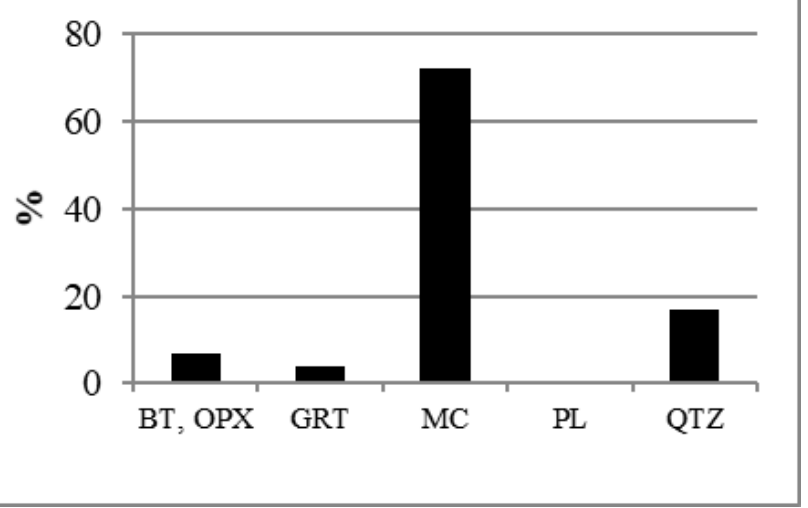

Figura 8 - Ocorrência, em porcentagem, dos minerais identificados no centro dos pontos de medição da cor na superfície das amostras submetidas ao ensaio de envelhecimento acelerado. Legenda: BT, OPX - Biotita e ortopiroxênio; GRT - Granada; Or - Ortoclásio; PL - Plagioclásio; QTZ - Quartzo.
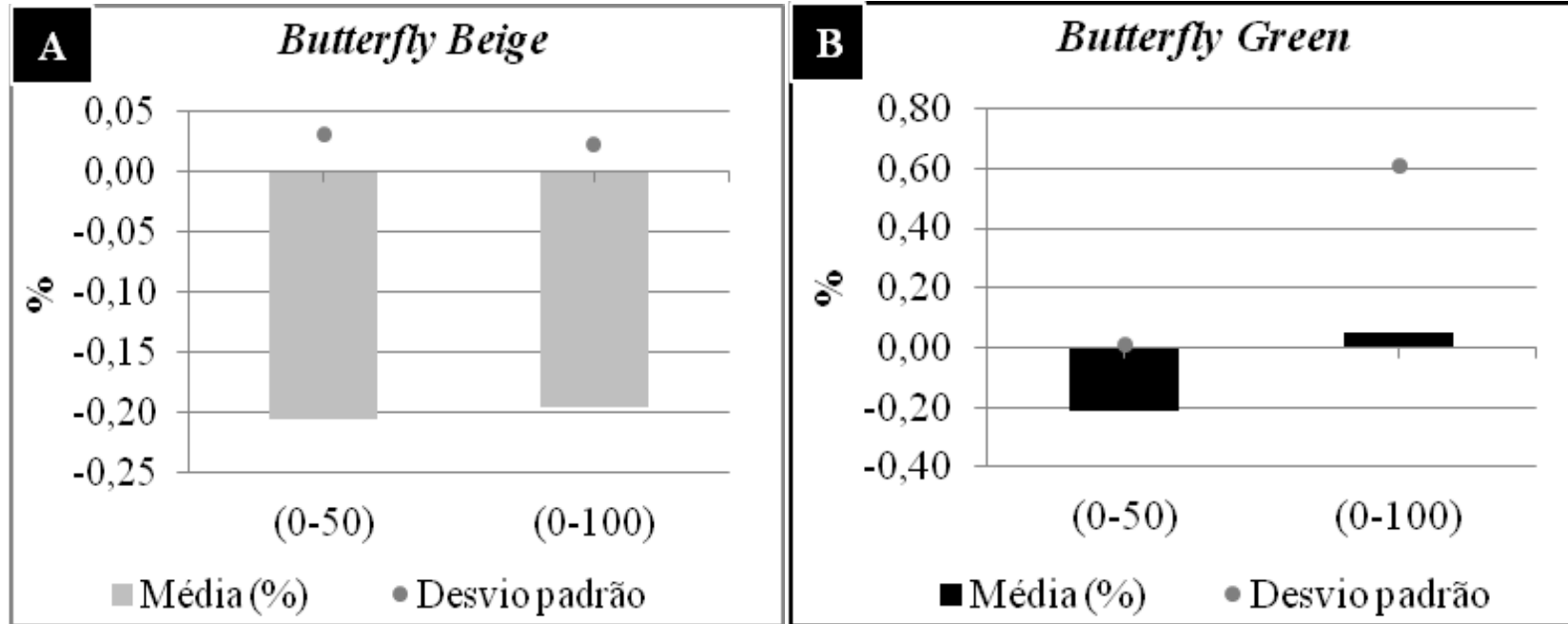

Figura 9 - Controle de massa das rochas submetidas aos ciclos de envelhecimento acelerado. 

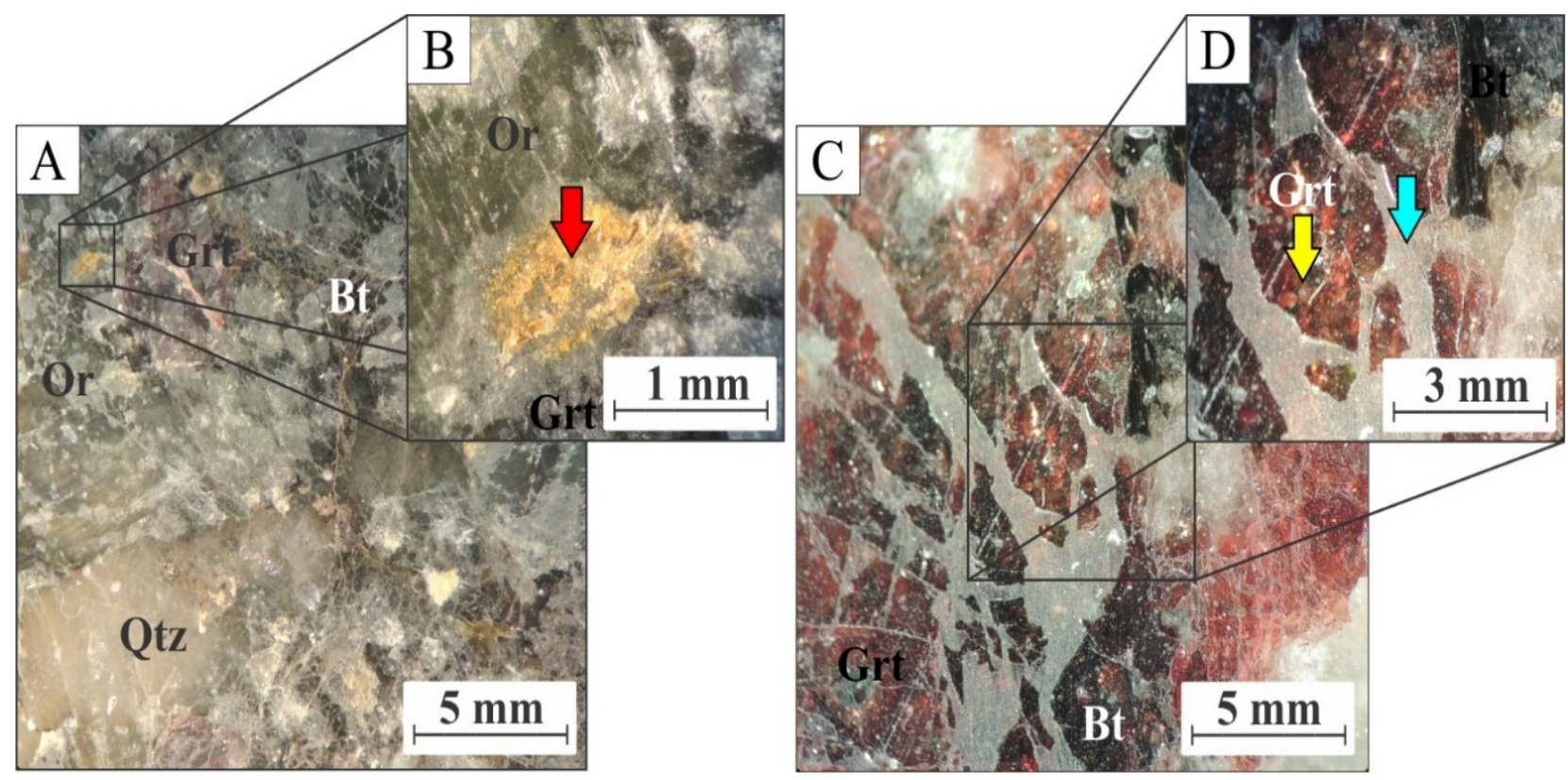

Figura 10 - Ilustração da cristalização de sulfetos (seta vermelha) e corrosões (seta amarela) no Butterfly Green. Legenda: Bt - Biotita; Grt - Granada; Or - Ortoclásio; Qtz - Quartzo; Azul - Corrosão superficial em granada.

Os desvios padrão mostram pouca dispersão entre os resultados para as amostras $(<1)$.

\section{Permeametria}

A permeametria mostrou para a amostras de Butterfly Green uma maior permeabilidade quando comparado a amostra de Butterfly Beige, principalmente nos primeiros 50 ciclos de envelhecimento (Figuras 11A, 11B).

Dos 50 ciclos para os 100 (Figura 11B) a hipótese da cristalização de sais na superfície na amostra, principalmente nas microfissuras, é confirmada, pois foi criada uma fina camada que funcionou como "impermeabilizante" impedindo que o gás penetrasse a amostra durante permeametria (Figura 12).

Ao analisar o gráfico de permeabilidade acumulada (Figura 11C) percebe-se a maior susceptibilidade à percolação de fluidos do

\section{Butterfly Green.}

Tal diferença se deve primeiro à presença, distribuída em todas as amostras do Butterfly Green, de microdescontinuidades sob a forma de planos de clivagem e microfissuras, como as mostradas na figura 13A e se deve também a grande quantidade de ortoclásio presente na rocha.

No Butterfly Green, os planos de clivagem dos minerais são preenchidos por $\mathrm{Fe}(\mathrm{OH})_{2}$. Já no Butterfly Beige, as microdescontinuidades (Figura 13B) correspondem às relações de intercrescimento mineral, exsolução, sob a forma de pertitas de cristais cálcio-sódicos dentro de cristais de ortoclásio.

A presença das pertitas na variedade Beige torna-a mais impermeável devido à ausência de fraturas.

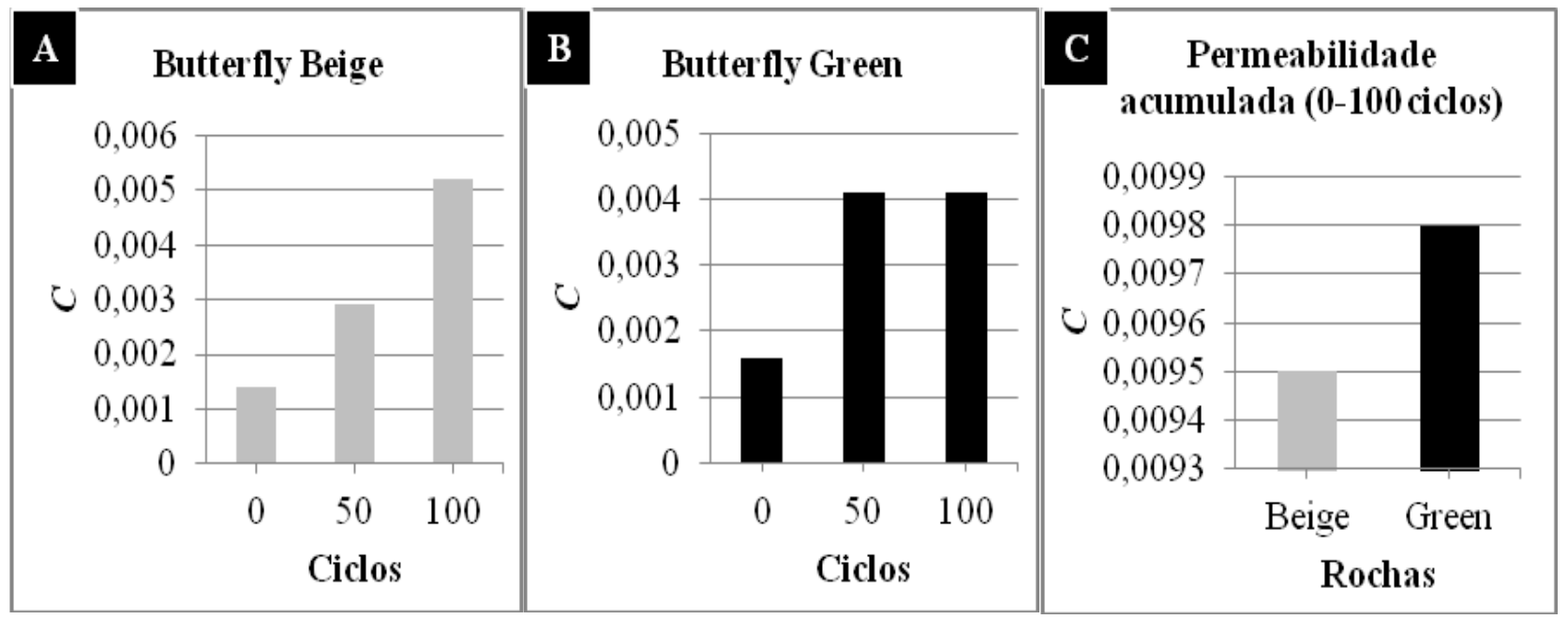

Figura 11 - Permeabilidades medidas ao longo dos ciclos de envelhecimento acelerado. 


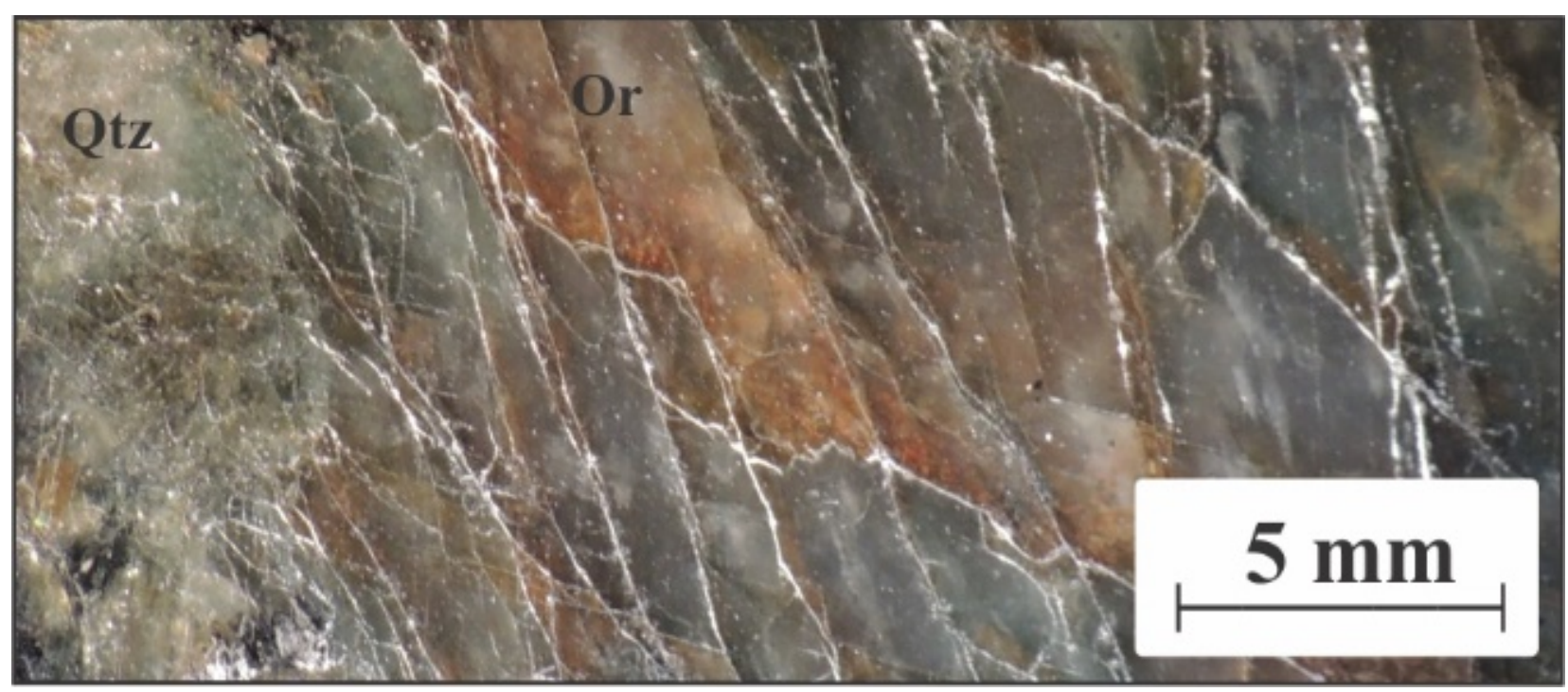

Figura 12 - Cristalização de sulfetos em descontinuidades em um ortoclásio.

Legenda: Or - Ortoclásio; Qtz - Quartzo.

\section{CONCLUSÕES}

O teste de envelhecimento acelerado mostrou sulfúrico presente nas chuvas ácidas. Os testes o quanto podem ser alteradas as superfícies de mostram que rochas de mesma gênese podem materiais pétreos expostos a ambientes físico- responder de forma diferente a solicitações químicos agressivos, a exemplo do ácido idênticas.

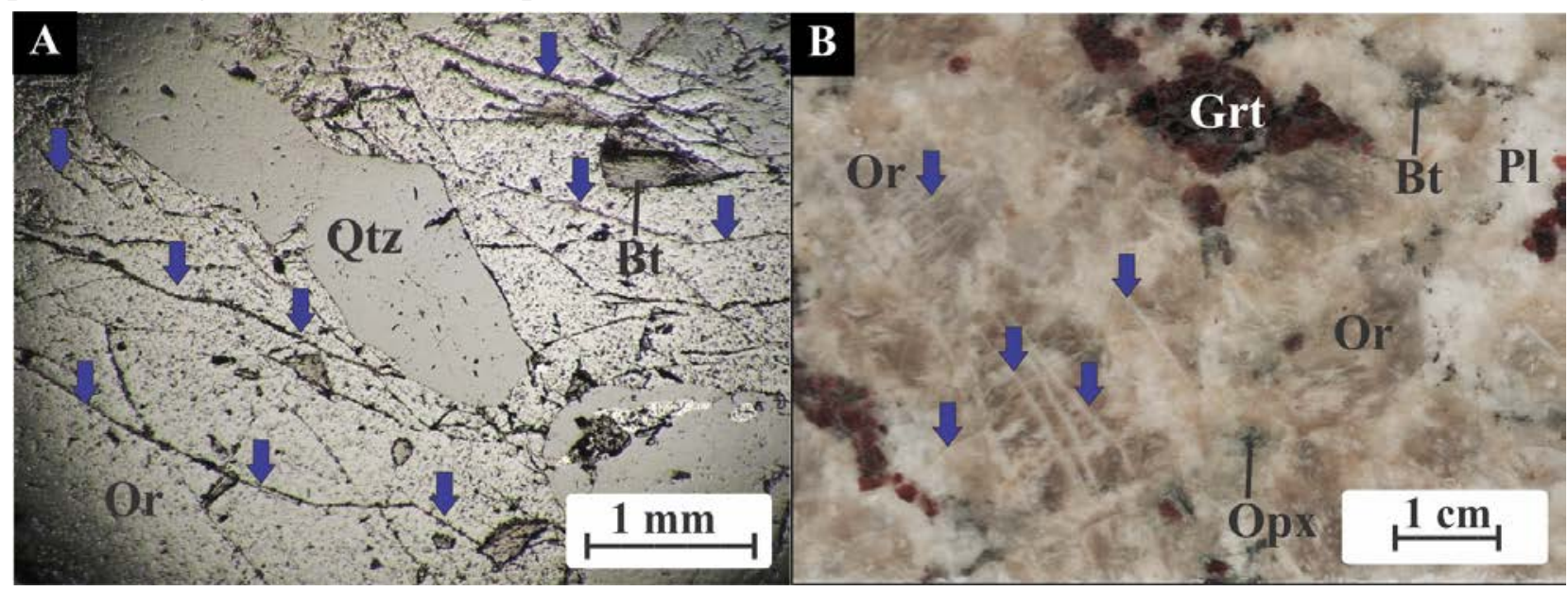

Figura 13 - Condições de preenchimento das microdescontinuidades nas rochas estudadas.

Legenda: Bt - Biotita; Grt - Granada; Or - Ortoclásio; Pl - Plagioclásio; Qtz - Quartzo. Setas Azuis: em (A) indicam microdescontinuidades abertas na variedade Green; em (B) indicam lamelas de exsolução na variedade Beige. A imagem (A) foi obtida com o posicionamento dos pontos de iluminação da lupa binocular, semi-paralelos às superfícies da rocha. A imagem (B) foi retirada, com iluminação direta, também com o uso de uma lupa binocular.

Este é o caso dos quartzo-sienitos com hiperstênio Butterfly Beige e Butterfly Green, rochas ornamentais extraídas em uma mesma pedreira, no município de Barra de São Francisco, Estado do Espírito Santo - Brasil.

No entanto, pequenas diferenças na distribuição mineralógica como, por exemplo, na distribuição do ortoclásio, e na condição de preenchimento das microdescontinuidades nestas rochas (Butterfly Green com hidróxido de Fe e Beige com lamelas de plagioclásio sódico exsolvidas) tornam-se características de fundamental importância na interpretação dos resultados obtidos.

A diferença de coloração entre as duas rochas, possivelmente proporcionada por evento hidrotermal na variedade bege que implicou mudanças químicas como a valência do $\mathrm{Fe}^{2+}$ (verde) para $\mathrm{Fe}^{3+}$ (bege) é característica marcante.

A gradação em campo destas colorações justifica tal entendimento. Além disso, inclusões originadas a partir da exsolução dificultaram a percolação de fluidos através dos cristais de ortoclásio da variedade bege, pois concentramse nas clivagens dos cristais de ortoclásio. 
Como a cor, na variedade verde é dada em função da presença do hidróxido ferroso nos planos de clivagem dos cristais de ortoclásio e a cor da variedade bege só não é verde por conta do hidrotermalismo que alterou o estado de oxidação do hidróxido e por conta do preenchimento dos planos de clivagem que não permitiu a percolação do hidróxido através dele com a mesma intensidade que ocorreu na variedade verde.

Esta constatação reforçaria a importância que a textura exerceria no comportamento da rocha, especificamente quanto a distribuição dos cristais de ortoclásio (determinantes para a cor final da rocha devido às suas dimensões e ao seu volume de ocorrência nas rochas).

A quantidade de ortoclásio presente nos pontos de medição de cor (72\% Green, 43\% Beige), tem ligação direta com os resultados obtidos para cor e permeabilidade dessas ao longo dos ciclos de envelhecimento acelerado, pois é o mineral que possui as microdescontinuidades que as diferenciam estruturalmente pelas condições de preenchimento.

A variação da temperatura, durante os ciclos de envelhecimento, pode ter funcionado como facilitadora da intrusão dos fluidos nas microdescontinuidades presentes, sobretudo no Butterfly Green, dilatando e contraindo cristais e, por consequência, abrindo fissuras não preenchidas.

As modificações de cor obtidas pelo Butterfly Green $(\Delta \mathrm{E}$ após 100 ciclos $=3,87)$ em relação ao Butterfly Beige mostram ( $\Delta \mathrm{E}$ após 100 ciclos $=2,18$ ) que está rocha necessita de maior cuidado na escolha do local de aplicação.

Locais úmidos e expostos à luz solar podem potencializar a ocorrência dos manchamentos (clareamentos) e corrosões (perda de lustro), principalmente em grandes centros ou nas proximidades de polos industriais, devido à maior concentração de $\mathrm{SO}_{2}$ na atmosfera nestes locais.

A permeabilidade medida indica maior susceptibilidade à percolação de fluidos para o Butterfly Green $(C=0,0097)$ mostrando que, além de ter sua superfície mais facilmente alterada, tais alterações podem penetrar mais em sua estrutura.

Esta constatação indica que maiores cuidados devem ser tomados ao aplicar estes materiais em ambientes externos em regiões onde a umidade é elevada e onde há concentrações elevadas de $\mathrm{SO}_{2}$ na atmosfera.

A presença do ácido sulfúrico, fotoquimicamente formado, na chuva ácida pode acarretar perda de brilho e aumento progressivo da permeabilidade, por isso aconselha-se aplicar estes materiais em ambientes internos.

\section{AGRADECIMENTOS}

À Guidoni Mineração Ltda pelo auxílio e cessão das amostras, à CAPES proc.: 3030/13-0, ao CNPq proc.: 141706/2012-0 pelas bolsas e ao Centro de Petrologia e Geoquímica do Instituto Superior Técnico de Lisboa, Portugal pela infraestrutura e pessoal disponibilizados à pesquisa.

\section{REFERÊNCIAS}

ALKIMIN, F.F.; PEDROSA-SOARES, A.C.; NOCE, C. M.; CRUZ, S.C.P. Sobre a evolução tectônica do Orógeno Araçuaí-Congo Ocidental. Geonomos, v. 15, n. 1, p. 24-43, 2007.

BOLONINI, T.M. \& GODOY, A.M. Caracterização Tecnológica dos Quartzo Sienitos com Hiperstênio Butterfly Beige e Butterfly Green. Geociências, v. 36, n. 3, p. 442-458, 2017.

BOLONINI, T.M. Estudo das Aplicações das Variedades de Um Quartzo Sienito Com Hiperstênio, Como Rochas Ornamentais, Com Auxílio da Caracterização Tecnológica e das Análises de Cor e Imagem. Rio Claro, 2015, 134 p. Tese de (Doutorado) - Instituto de Geociências e Ciências Exatas-Universidade Estadual Paulista

BOLONINI, T.M., GODOY, A.M., FIGUEIREDO, C.A.M., MAURÍCIO, A., PEREIRA, M.F., CLEMENTE, I.M., SILVA, F.D.O. Análises de cor e Imagem das Rochas Ornamentais Butterfly Beige, Butterfly Gold e Butterfly Green expostas a altas temperaturas. Geociências, v. 36, n. 4, p. 703716, 2017.

BOLONINI, T.M.; GODOY, A.M.; BOLONINI, L.C.A.S.; SILVEIRA, L.L.L.; SANTOS, E. Análise de cor em imagens digitais e análise de brilho para rochas ornamentais submetidas ao ataque químico. In: SIMPÓSIO DE ROCHAS ORNAMENTAIS DO NORDESTE, IX, João Pessoa, 2016a. Anais... João Pessoa: CETEM, 2016a.

BOLONINI, T.M.; GODOY, A.M.; BOLONINI, L.C.A.S.; SILVEIRA, L.L.L.; SANTOS, E. Quantificação mineralógica modal macroscópica, em rochas ornamentais submetidas à coloração seletiva por ataque químico, através da classificação supervisionada de imagens. In: SIMPÓSIO DE ROCHAS ORNAMENTAIS DO NORDESTE, IX, João Pessoa, 2016b. Anais... João Pessoa: CETEM, 2016b.

BOLONINI, T.M.; GODOY, A.M.; BOLONINI, L.C.A.S.; SILVEIRA, L.L.L.; SANTOS, E. Uso da correlação entre imagens na classificação da descaracterização superficial de rochas ornamentais submetidas ao ataque químico. In: SIMPÓSIO DE ROCHAS ORNAMENTAIS DO NORDESTE, IX. João Pessoa, 2016c. Anais... João Pessoa: CETEM, 2016c.

CEN199X. Comité Européen de Normalisation.Methods of test for natural Stone part XI, accelerated decay test by temperature, humidity and sulphur dioxidium. Europaische Norm. 7p. 1995. 
CPRM. Serviço Geológico do Brasil. Geologia da Folha de Mantena - SE.24-Y-A-VI - Programa Geologia do Brasil nota explicativa da folha Mantena. Escala 1:100.000, 2007.

FIGUEIREDO, C.A.M.; FIGUEIREDO, P.; AIRES-BARROS, L.; PINA, P.; RAMOS, V. Texture analysis of images taken from artificially aged Stones: a statistical and structural approach. In: Restoration of Buildings and Monuments. An international Journal, v 11, n. 4, p. 235-245, 2005.

FIGUEIREDO, P.; FIGUEIREDO, C.A.; AIRES-BARROS, L.; FLAMBÓ, A. Contribuição para o estudo cromático das rochas da capela do Palácio da Bemposta. Proelium, Revista da Academia Militar. VI série, n. 1, p. 168-178, 2004.

GROSSI, C.; HUNT, B.; SMART, S. Urban pollution and stone decay. Natural Stone Specialist, v. 34, n. 7, p. 22-32, 1999.

HUNTERLAB. Insigth on Color. Applications Note, v. 8, n. 7, 4p., 2008.

KASAHARA, M. \& TAKAHASHI, K. Experimental studies on aerosol particle formation by sulfur dioxide. Atmospheric Environment, v. 10. p. 475-486, 1976.

MARSHAK, S.; ALKIMI, F.F.; WHITTINGTON, A.; PEDROSA-SOARES, A.C. Extensional collapse in the Neoproterozoic Araçuaí orogen, eastern Brazil: a setting for reactivation of asymmetric crenulation cleavage. Journal of Structural Geology, v. 28, p. 129-147, 2006.

MARTINS, V.T.S.; TEIXEIRA, W.; NOCE, C.M.; PEDROSASOARES, A.C. Sr and Nd Characteristics of Brasiliano/PanAfrican Granitoid Plutons of the Araçuaí Orogen, Southeastern Brazil: Tectonic Implications. Gondwana Research, v. 7, n. 1, p. 75-89, 2004.

MCGRAW, R. Condensation Nuclei Production from Sulfur Dioxide Photo-oxidation In Air. Journal of. Physical Chemistry, v. 86, p. 2750-2752, 1982.

NOCE, C.M.; PEDROSA-SOARES, A.C.; SILVA, L.C. DA; ARMSTRONG, R.; PIUZANA, D. Evolution of polycyclic basement complexes in the Araçuaí Orogen, based on U-Pb SHRIMP data: Implications for Brazil- Africa links in Paleoproterozoic time. Precambrian Research, v. 159, p. 60 78, 2007.

PEDROSA-SOARES, A.C.; CASTAÑEDA, C.; QUEIROGA, C.; GRADIM, C.; BELÉM, J.; RONCATO, J.; NOVO, T.; DIAS, P.; GRADIM, D.; MEDEIROS, S.; JACOBSOHN, T.; BABINSKI, M.; VIEIRA, V. Magmatismo e tectônica do Orógeno Araçuaí no extremo Leste de Minas e Norte do Espírito Santo $\left(18^{\circ}-19^{\circ} \mathrm{S}, 41^{\circ}-40^{\circ} 30^{\prime} \mathrm{W}\right)$. Geonomos, v. $14, \mathrm{n}$. 1, 2, p. 97-111, 2006

PEDROSA-SOARES, A.C.; NOCE, C.M.; ALKIMIM, F.F.; SILVA, L.C.; BABINSKI, M., CORDANI, U.; CASTAÑEDA, C. Orógeno Araçuaí: Síntese do Conhecimento 30 anos após Almeida 1977. Geonomos, v. 15, n. 1, p. 1-16, 2007.
PEDROSA-SOARES, A.C.; NOCE, C.M.; VIDAL, P.H.; MONTEIRO, R.L.B.P.; LEONARDOS, O.H. Toward a new tectonic model for the Late Proterozoic Araçuaí (SE Brazil) West Congolian (SW Africa) Belt. Journal of South American Science, v. 6, n. 1/2, p. 33-47, 1992.

PEDROSA-SOARES, A.C.; NOCE, C.M.; WIEDEMANN, C.M.; PINTO, C.P. The Araçuaí-West-Congo Orogen in Brazil: an overview of a confined orogen formed during Gondwanaland assembly. Precambrian Research, v. 110, p. 307-323, 2001.

PMI. Porous Materials Inc. Gas Permeameter. User’s Manual. Version 6.0, 61p., 1996.

RONCATO JÚNIOR, J.G. As Suítes Graníticas Tipo-S do norte do Espírito Santo na região das Folhas Ecoporanga, Mantena, Montanha e Nova Venécia. Belo Horizonte, 2009, 103p. Dissertação (Mestrado em Geociências) - Instituto de Geociências, Universidade Federal de Minas Gerais.

SETHI, D.S. Photo-Oxidation of Sulfur Dioxide. Journal of the Air Pollution Control Association, v. 21, p. 7, 418-420, 1971.

SIMÃO, J.A.R.S. Rochas ígneas como pedra ornamental Causas, condicionantes e mecanismos de alteração. Implicações tecnológicas. 2003, 202p. Lisboa. Dissertação. Universidade Nova de Lisboa, Faculdade de Ciências e Tecnologia, Portugal.

SIMÃO, J.A.R.S.; CARVALHO, C.; MOURA, A.C. Factor de qualidade em rochas ornamentais com base em ensaios mecânicos e envelhecimento artificial. Geotecnia, Laboratório Nacional de Energia e Geologia - LNEG, Portugal, 13p., 2010

TAKAHASHI, K.; KASAHARA, M.; ITOH, M.A. kinetic model of sulfuric acid aerosol formation from photochemical oxidation of sulfur dioxide vapor. Aerosol Science, v. 6, p. 45-55, 1975a.

TAKAHASHI, K.; KASAHARA, M.; ITOH, M.A. kinetic model of sulfuric acid aerosol formation from photochemical oxidation of sulfur dioxide vapor. Note, Correspondence. Aerosol Science, v. 6, p. 483-485, 1975 b.

TORQUATO, M.F.B.; TORQUATO, J.R.F.; FIGUEIREDO, C.A.M.; NOGUEIRA NETO, J.A.N. Estudo dos granitos cearenses "Vermelho Filomena, Meruoca Clássico e Verde Ceará” por análise digital de imagem em câmara com atmosfera satura em $\mathrm{SO}_{2}$. Geonomos, v 16, n. 2, p. 51-52, 2008. 